\title{
Evaluación de un nuevo dispositivo de conexión para los catéteres de hemodiálisis
}

Jorge Bort Castelló - Carmen Salvador Lengua - Alexandra Mallol Domínguez - Jesús Carratalá Chacón - Vicente Cerrillo García - Ma José Folch Morro - Elena Renau Ortells - Carmen Aicart Saura Martina Magriñan Orenga

Unidad de Hemodiálisis. Hospital General de Castellón

\section{Resumen}

Los pacientes en hemodiálisis tienen cada vez una edad más avanzada y esto hace que aumente el número de complicaciones en su acceso vascular. Las infecciones de los catéteres tunelizados provocan una alta morbi-mortalidad.

El dispositivo conector de sellado microbiológica y mecánicamente $\mathrm{TEG}^{\circledR}$ se utiliza en sustitución del tapón convencional con el que se cierran las luces del catéter presentando la ventaja de que sólo se cambia una vez a la semana. Esto hace que al existir menos manipulación de la vía central aparezcan menos complicaciones e infecciones. Además ofrece una doble barrera de seguridad a la entrada de aire y salida de sangre representadas por la pinza del catéter y el tapón.

Para evaluar este dispositivo hemos realizado un estudio en el cual comparamos los tapones TEG ${ }^{\circledR}$ con los tapones convencionales, analizando los siguientes aspectos: presiones del circuito, eficacia dialítica e infecciones del catéter. El estudio tuvo una duración de dos meses y en él participaron doce pacientes portadores de catéter tunelizado.

Correspondencia:

Jorge Bort Castelló

Unidad de Hemodiálisis.

Hospital General de Castellón

Av. Benicàssim s/n

12004 Castellón

jordibort2@hotmail.com
Nuestros resultados indican que no existen diferencias significativas en cuanto a las presiones del circuito y a la eficacia dialítica entre ambos tipos de tapones. Durante el estudio no hubo ninguna infección pericatéter.

Creemos que el dispositivo TEG0 ${ }^{\circledR}$ por sus especiales características, puede ser el sistema de cierre ideal para todo tipo de catéteres.

\section{PALABRAS CLAVE: \\ - CATÉTER \\ - INFECCIÓN \\ - EFICACIA DIALÍTICA \\ - HEMODIALISIS \\ - PRESION TRANSMEMBRANA \\ - TEGO ${ }^{\circledR}$}

\section{Evaluation of a new haemodialysis catheter connector}

\section{Abstract}

Patients on haemodialysis are becoming increasingly older and this means there is an increase in the number of vascular access complications. Infections of tunnelled catheters cause a high morbidity/mortality.

The $\mathrm{TEGO}^{\circledR}$ microbiologically and mechanically sealed connector is used instead of the conventional 
cap used to close the catheter ends, and has the advantage that it is only changed once a week. This means that as there is less handling of the central venous catheter, fewer complications and infections appear. It also offers a double security barrier against the entry of air and exit of blood represented by the catheter clamp and the cap.

To evaluate this device, we have carried out a study in which we compared the TEG ${ }^{\circledR}$ connectors with conventional caps, analysing the following aspects: circuit pressures, dialysis efficacy and catheter infections. The study lasted for two months and included the participation of twelve patients using a tunnelled catheter.

Our results show that there are no significant differences with regard to circuit pressures and dialysis efficacy between the two different types of caps. During the study there was no pericatheter infection.

We believe that the TEGO ${ }^{\circledR}$ device, on account of its special characteristics, may be the ideal closure system for all kind of catheters. hemodiálisis crónica contraen infecciones sanguíneas debidas al catéter ${ }^{2,3}$. La enfermería desempeña un papel fundamental para minimizar este riesgo y sus complicaciones aplicando sus conocimientos mediante un seguimiento y protocolización.

Recientemente hemos comenzado a utilizar en nuestra unidad un dispositivo de conector sellado microbiológica y mecánicamente TEGO ${ }^{\circledR}$, ICU Medical (figura 1), en pacientes con CVC sometidos a hemodiálisis periódica. El dispositivo $\mathrm{TEGO}^{\circledR}$ incorpora una conexión "luer hembra", normalmente cerrada y una conexión "luer macho" que se conecta a las conexiones de un CVC. La conexión hembra posee una válvula que se cierra al retirar la jeringa o la línea con lo cual se disminuye el número de veces que la luz del catéter queda expuesta al exterior, además se evita el reflujo de la sangre hacia la luz del catéter. Este dispositivo se usa en sustitución del clásico tapón con el que tapamos las luces del CVC una vez terminada la HD, y presenta la ventaja de que solo se cambia una vez a la semana. Esto hace que, al existir una menor manipulación de la vía central pueden existir menos complicaciones e infecciones, por lo cual decidimos realizar este estudio.

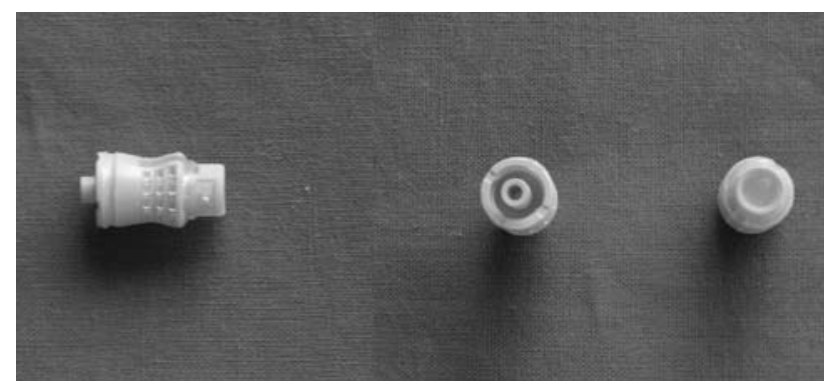

Figura 1. Tapón TEG0 ${ }^{\circledR}$

\section{Introducción}

Los pacientes en hemodiálisis tienen cada vez una edad más avanzada. Este hecho hace que aumente el número de complicaciones en su acceso vascular. Los catéteres permanentes tunelizados son una de las posibles opciones, pero presentan complicaciones como las infecciones, las cuales provocan una alta morbi/mortalidad. La bacteriemia es una complicación frecuente asociada al catéter permanente tunelizado ${ }^{1}$. Según diversos estudios el $10 \%$ de los pacientes con catéter venoso central (CVC) permanente sometidos a

\section{Objetivos}

1. Comparar si hay diferencias entre los tapones TEG $0^{\circledR}$ y los tapones normales en los siguientes aspectos:

- Presiones del circuito

- Eficacia dialítica

- Infecciones del catéter

2. Valorar la utilidad de la técnica y su procedimiento mediante un seguimiento y aplicación del protocolo de conexión de catéteres de nuestra unidad. 


\section{Material y métodos}

Se incluyeron 12 pacientes ( 9 hombres y 3 mujeres) con insuficiencia renal crónica terminal en hemodiálisis portadores de catéteres permanentes tunelizados; el estudio se realizó en dos fases de un mes.

- Primer mes: aplicación de protocolo de conexión y desconexión de catéteres de nuestra unidad cerrando el catéter con el sistema de tapón convencional. El tapón se cambiaba todas las sesiones de la semana.

- Segundo mes: aplicación de protocolo de conexión y desconexión de catéteres de nuestra unidad aplicando un dispositivo de protección, específicamente diseñado para catéteres de hemodiálisis. Este tapón crea un sistema cerrado de forma microbiológica y mecánica que protege al catéter de toda contaminación. El tapón solo se cambiaba el primer día de la semana.

Durante todo el estudió se realizaron el primer día de cada semana cultivos de cada ramal y del orificio de inserción del catéter. Así como un control del exudado nasal al mes.

Todos los pacientes realizaron su pauta habitual de diálisis: tiempo $203,42 \pm 95,54 \mathrm{~min}$, el flujo de baño $650,6 \pm 145$, dializador HF60® el 23,43\%; HF80® el $23,43 \%$; Arylane $\mathrm{H} 9 \circledast$ el $41,87 \%$ y Nephral $500 \AA$ el $11,25 \%$. El tipo de catéter implantado era Arrow ${ }^{\circledR}$ en todos los casos. Fueron localizados en yugular derecha $81,87 \%$; yugular izquierda $22,11 \%$. El monitor, dializador, líneas y las técnicas "on line", biofiltración y AFBK según cada caso fueron las pautas habituales de tratamiento.

Se confeccionó una hoja de recogida de datos diaria en la que constaba: nombre del paciente, fecha, monitor utilizado, peso seco, peso pre y post hemodiálisis, ultrafiltración, presiones venosas y arteriales a los $5^{\prime}$, $60^{\prime}, 120^{\prime}, 180^{\prime}, 240^{\prime}$, tensión y frecuencia cardiaca pre y post hemodiálisis, coagulación de las líneas arterial, venosa y dializador, dosis administración de heparina, tipo de catéter y localización, resultado del cultivo del orificio semanal, cultivo conexiones catéter semanal exudado nasal mensual y KTV mensual.

Para la utilización del nuevo tapón se requiere una técnica aséptica siguiendo los siguientes pasos:
- Se retira el conector $T E G{ }^{\circledR}$ de su envase utilizando una técnica aséptica.

- Se conecta al dispositivo de acceso vascular.

- El sello de silicona del tapón se desinfecta antes de cada uso (preferiblemente con un desinfectante alcohólico).

- Se conecta una jeringa, se aspira la heparina del sellado y se desecha.

- Se conecta una jeringa con 10 cc. de suero fisiológico y se lava cada ramal del catéter.

- Se enrosca el cuello giratorio de la línea de sangre hasta que se detenga (no apretar en exceso) y se inicia la diálisis.

El protocolo de conexión consiste en conectar y desconectar al paciente mediante dos personas, aplicando las máximas medidas de asepsia. El que manipula el catéter realiza lavado de manos, y se reviste con bata, gorro, mascarilla y guantes estériles. El acompañante que complementa la técnica, previo lavado de manos permanece con mascarilla, guantes y gorro. El paciente permanece con mascarilla y gorro. Para la manipulación del catéter se requiere un set de diálisis.

\section{Resultados}

El flujo de sangre $(Q B)$ medio fue de: $332,96 \pm 23,73$. No se detectaron diferencias significativas en las presiones venosas siendo éstas un poco más elevadas en los tapones $\mathrm{TEGO}^{\circledR}$ (figura 2). Las presiones arteriales también fueron más elevadas en los tapones $\mathrm{TEGO}^{\circledR}$, aunque tampoco el resultado obtenido es significativo (figura 3). EI KTV ha sido el adecuado con ambos tapones (figura 4).

Los cultivos de las conexiones externas de los catéteres fueron negativos en los dos tipos de tapones. Los exudados nasales de los pacientes que llevaban los tapones convencionales fueron positivos en el $10 \%$ y con los tapones $\mathrm{TEGO}^{\circledR}$ el $37,5 \%$. Todos ellos se trataron con pomada Bactroban nasal, durante una semana. En cuanto al orificio de salida fueron positivos el $44,89 \%$ en los tapones convencionales y en los tapones $\mathrm{TEGO}^{\circledR}$ el $36 \%$. Las bacterias localizadas fueron staphylococus epidermis, staphylococus species y corynebacterium species. 


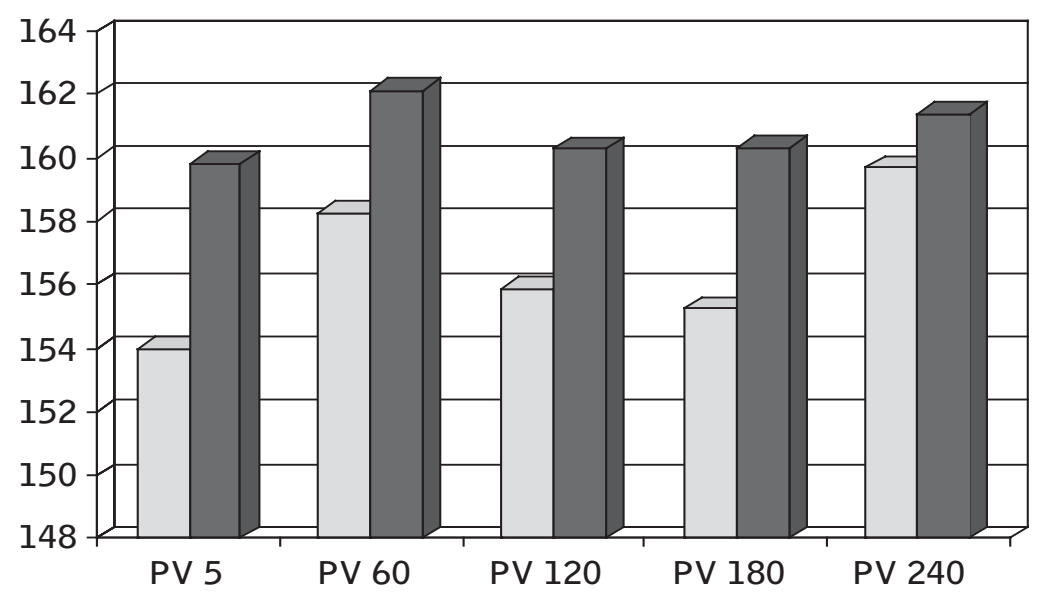

Figura 2. Relación de las presiones venosas medidas en $\mathrm{mmHg}$ en los tiempos en que fueron medidos

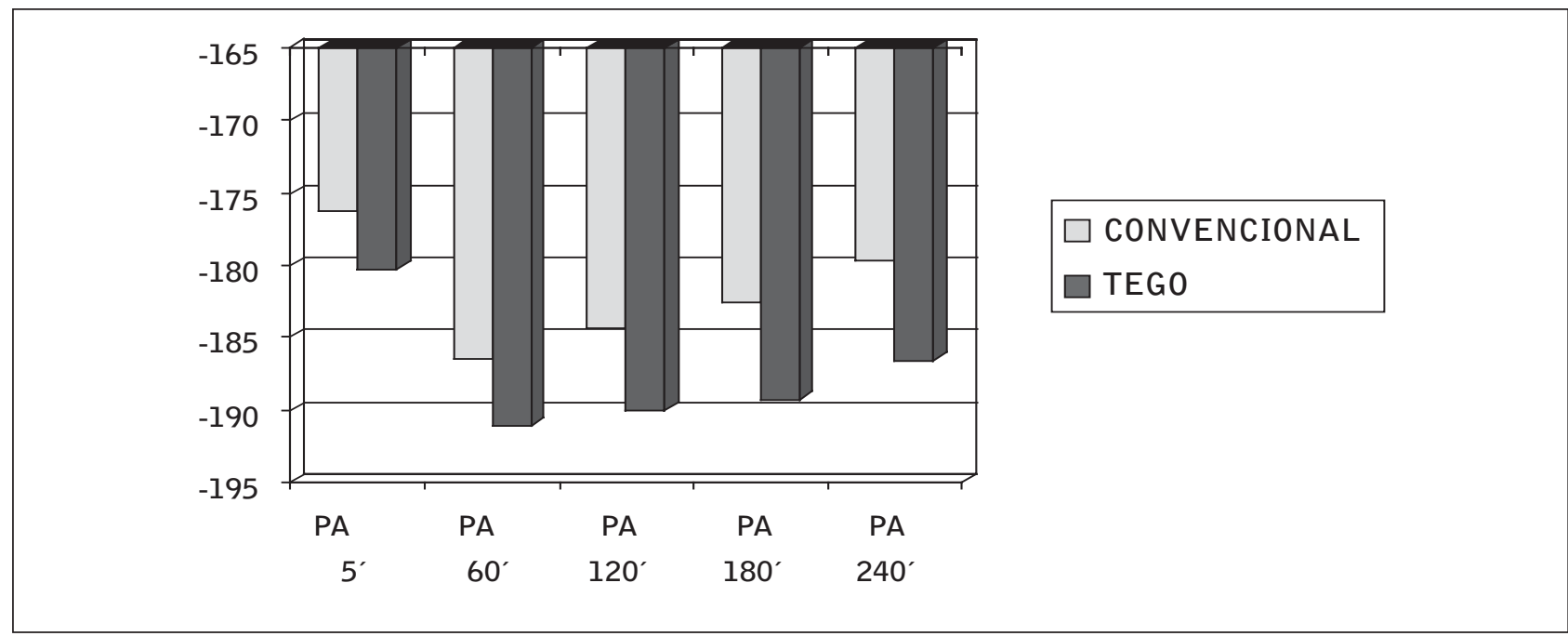

Figura 3. Relación de las presiones arteriales medidas en $\mathrm{mmHg}$ en los tiempos en que fueron tomados los valores

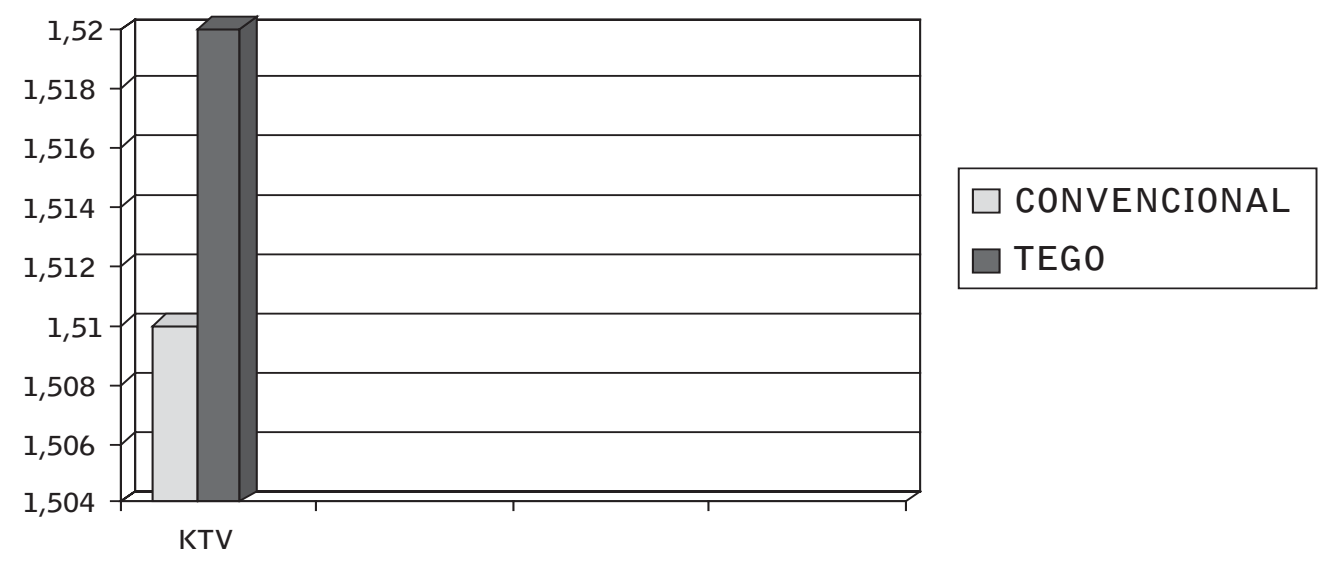

Figura 4. Relación de los valores del Ktv con el tapón $T E G 0^{\circledR}$ y con el tapón convencional 


\section{Discusión/Conclusiones}

Al existir una menor manipulación de una vía central pueden aparecer menos complicaciones e infecciones. El conector, al estar provisto de un sistema anti-reflujo, posee menor riesgo de entrada de aire en el catéter en el instante de la conexión, si se da la circunstancia de olvido de cierre de la pinza de seguridad de cada ramal. Al cambiar el tapón $\mathrm{TEGO}^{\circledR}$ una sola vez a la semana, se evitan las posibles fisuras que se pudiesen originar en las conexiones externas del catéter, debido a las múltiples conexiones de líneas y tapones, ya que las líneas van conectadas al tapón. Es conocido que las múltiples manipulaciones de los conectores de los CVC por los profesionales sanitarios aumenta el riesgo de contaminación intraluminal ${ }^{4}$.

A pesar de los resultados positivos de los exudados nasales en algunos pacientes no han tenido ninguna influencia, ya que fueron tratados precozmente y se evitó posibles infecciones de los catéteres. Durante el estudio no hubo ninguna infección sintomática que precisara ser tratada, pese al importante número de cultivos del orificio de salida positivos.

Por tanto se puede afirmar que no existen diferencias significativas en cuanto a las presiones del circuito y eficacia dialítica entre ambos tipos de tapones. Al utilizar el nuevo conector se reducen las manipulaciones en las vías del catéter cosa que siempre disminuirá el riesgo de infección ya que con el tapón $\mathrm{TEGO}^{\circledR}$ existe una doble barrera de seguridad a la entrada de aire y salida de sangre a través de los ramales del catéter. Por todo ello creemos que estos tipos de dispositivos pueden ser el sistema de cierre ideal para todo tipo de catéteres.

\section{Bibliografía}

1. Moya Mejía C et. al. Monitorización sistemática del catéter permanente: una herramienta útil en el estudio de la tasa de infección y disfunción en dos tipos de catéteres tunelizados. Libro de comunicaciones del XXX Congreso nacional de la SEDEN. Málaga, Octubre 2005.

2. Gessaroli G, Galli F, Mundolfo S. Accessi Vascolari Per Emodialisi. Edition; 2001. p. 1-34.

3. Soad TF. Bacteriemia Associated with Tunneled, Cuffed. Hemodiálysis Catheter Am J Kidney Dis 1999; 34:114-24.

4. Bouza E, Muñoz P, López-Rodríguez J, et al. A Needleless Closed System Device (CLAVE) Protects from Intravascular Catheter Tip and Tub Colonization: A Prospective Randomized Study. Journal of Hospital Infection 2003; 54, 279-287. 